This item was submitted to Loughborough's Research Repository by the author.

Items in Figshare are protected by copyright, with all rights reserved, unless otherwise indicated.

\title{
Putting personalisation into practice: work-focused interviews in Jobcentre
}

\section{Plus}

PLEASE CITE THE PUBLISHED VERSION

http://dx.doi.org/10.1017/S0047279412000980

PUBLISHER

(c) Cambridge University Press

VERSION

VoR (Version of Record)

LICENCE

CC BY-NC-ND 4.0

REPOSITORY RECORD

Toerien, Merran, Roy Sainsbury, Paul Drew, and Annie Irvine. 2019. "Putting Personalisation into Practice: Work-focused Interviews in Jobcentre Plus". figshare. https://hdl.handle.net/2134/13228. 
This item was submitted to Loughborough's Institutional Repository (https://dspace.lboro.ac.uk/) by the author and is made available under the following Creative Commons Licence conditions.

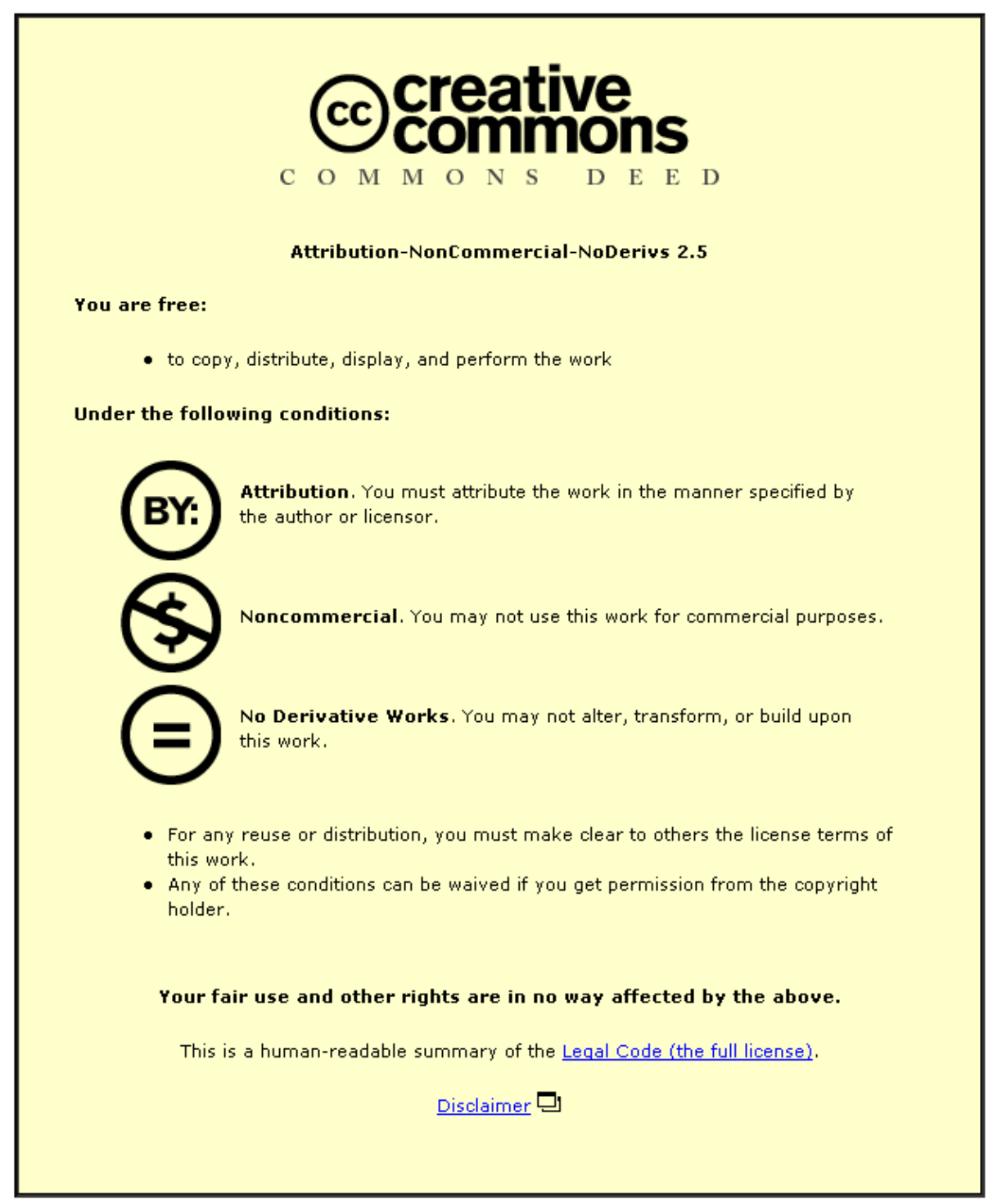

For the full text of this licence, please go to: http://creativecommons.org/licenses/by-nc-nd/2.5/ 


\section{Journal of Social Policy}

http://journals.cambridge.org/JSP

Additional services for Journal of Social Policy:

Email alerts: $\underline{\text { Click here }}$

Subscriptions: $\underline{\text { Click here }}$

Commercial reprints: Click here

Terms of use : $\underline{\text { Click here }}$

\section{Putting Personalisation into Practice: Work- Focused Interviews in Jobcentre Plus}

MERRAN TOERIEN, ROY SAINSBURY, PAUL DREW and ANNIE IRVINE

Journal of Social Policy / Volume 42 / Issue 02 / April 2013, pp 309 - 327

DOI: 10.1017/S0047279412000980, Published online: 28 January 2013

Link to this article: http://journals.cambridge.org/abstract_S0047279412000980

How to cite this article:

MERRAN TOERIEN, ROY SAINSBURY, PAUL DREW and ANNIE IRVINE (2013). Putting Personalisation into Practice: Work-Focused Interviews in Jobcentre Plus. Journal of Social Policy, 42, pp 309-327 doi:10.1017/S0047279412000980

Request Permissions : $\underline{\text { Click here }}$ 


\title{
Putting Personalisation into Practice: Work-Focused Interviews in Jobcentre Plus
}

\author{
MERRAN TOERIEN*, ROY SAINSBURY**, PAUL DREW*** and \\ ANNIE IRVINE****
}

\author{
* Merran Toerien, Department of Sociology, The University of York, Heslington, York, YO10 \\ $5 D D, U K$ \\ email:merran.toerien@york.ac.uk \\ ${ }^{* *}$ Roy Sainsbury, Social Policy Research Unit, The University of York, Heslington, York, YO10 \\ $5 D D, U K$ \\ email: roy.sainsbury@york.ac.uk \\ *** Paul Drew, Department of Social Sciences, Loughborough University, Leicestershire, \\ LE11 3TU, UK. (please note that at the time of conducting the research reported here, Paul \\ Drew was based in the Department of Sociology, The University of York.) \\ email: p.drew@lboro.ac.uk \\ ${ }^{* * * *}$ Annie Irvine, Social Policy Research Unit, The University of York, Heslington, York, YO1O \\ $5 D D, U K$ \\ email: annie.irvine@york.ac.uk
}

\begin{abstract}
The principle of personalisation is widespread across the UK's public sector, but precisely what this means is unclear. A number of theoretical typologies have been proposed but there has been little empirical study of how personalisation is translated into practice on the frontline. We address this gap through analysis of a unique dataset: over 200 audio and video recordings of work-focused interviews in Jobcentre Plus offices. Through detailed analysis of these recordings, we show that personalisation reflects two key dimensions: the substantive (what advisers do) and the procedural (how they do it). We illustrate these dimensions, showing how each represents a continuum, and propose a typology of personalisation in practice, reflecting how the dimensions interact. We conclude with some thoughts on the relevance of our findings for advisory practice in the future under the Coalition government's new Work Programme.
\end{abstract}

\section{Introduction}

We've changed our service deliberately to make it a lot more personalised. We can offer much more help tailored around the individual's circumstances than ever before. (Ruth Owen, Chief Operating Officer for Jobcentre Plus, quoted by Waite, 2009)

We will create a Work Programme which will move toward a single scheme that will offer targeted, personalised help for those who need it most, sooner rather than later. (Iain Duncan Smith, Secretary of State for Work and Pensions, 2010)

The principle of personalisation - that services 'should respond to the individual instead of the person having to fit with the service' (Carr, 2008: 3 ) - is widespread 
across the UK's public sector and is consistent with the growth and influence of 'New Public Management' principles in the UK over the past twenty-five years or so (Christensen and Laegreid, 2011). Although most closely associated with the New Labour government's personal budgets in adult social care, personalisation is also 'shaping approaches to reform in the NHS, children's services, education, employment, housing and criminal justice' (Needham, 2011: 55) and the concept enjoys significant cross-party support. As Mansell and Beadle-Brown (2005: 21) put it: 'There is now no serious alternative to the principle that services should be tailored to individual needs, circumstances and wants.' But what does personalisation really mean? Considerable effort has gone into answering this question in theoretical terms. A common finding is that the concept is used, especially in policy documents, in ambiguous, elastic and sometimes contradictory ways (e.g. Borghi and van Berkel, 2007; Cribb and Owens, 2010; Cutler et al., 2007; Ferguson, 2007; Pykett, 2009; Valkenburg, 2007; and see Greener and Powell, 2008, for a related discussion of the concept of choice). Various typologies have been proposed, with Leadbeater's (2004) probably the best-known in the UK. These generally imply a continuum from 'passive' to more 'active' forms of participation by (potential) service users (Borghi and van Berkel, 2007). However, there has been little empirical study of how the personalisation principle is put into practice by public service providers on the frontline. This is crucial because, as Lipsky (2010) famously argued, public policy is made not only in government departments but also at 'street level' - 'in the daily encounters between the public and staff in schools, hospitals, welfare-to-work programmes or the legal courts' (McNeil, 2009: 9).

This paper addresses this gap in our understanding using a unique dataset: over 200 audio and video recordings of work-focused interviews (WFIs) in Jobcentre Plus offices. Jobcentre Plus is the organisation responsible, since 2002, for administering the UK's state benefits system and providing public services to support claimants into work. A central goal is to provide 'personalised support for everyone' (McNeil, 2009: 5). The main mechanism for realising this is the personal adviser, who is tasked with providing one-to-one support for claimants through work-focused interviews. Most claimants have to attend at least one such interview in order to receive benefits (Karagiannaki, 2007). In 2009, Jobcentre Plus (JCP) advisers conducted an average of almost 950,000 work-focused interviews per month (McNeil, 2009). Interviews typically include discussion of a claimant's skills, work experience, aspirations and barriers to work, and vary in length, regularity and content, depending on the type of benefit being claimed. Information provision, advice-giving, helping claimants to search for jobs and making referrals to appropriate support programmes are all part of an adviser's role.

Work-focused interviews offer an ideal opportunity to study personalisation in practice for several reasons. First, welfare reform policies in the UK have, 
for over a decade, been underpinned by this principle. Significant supporting documents include a 1998 Green Paper (DSS, 1998), which made the case for 'developing flexible personalised services to help people into work' (Stafford and Kellard, 2007: 130); subsequent Green and White papers, No One Written Off (DWP, 2008a) and Raising Expectations and Increasing Support (DWP, 2008b); the Freud (2007) report, which recommended more individualised support for the 'harder to help'; and the Gregg (2008) review, which laid out a 'vision for personalised conditionality and support'. Personalisation also remains significant in the post-2010 Coalition government's plans for reform.

Second, the personal adviser role, outlined above, was created specifically to realise the principle of personalisation in practice (McNeil, 2009). Third, in accordance with this principle, there has been an increasing emphasis within Jobcentre Plus and its parent organisation, the Department for Work and Pensions - on enabling 'adviser discretion' in dealing with claimants. For example, the 'Jobcentre Plus offer', introduced in April 2011, 'aims to allow more flexibility to Jobcentre Plus managers and advisers to judge which interventions will help individual claimants most cost effectively' (Bellis et al., 2011: 12). Possible interventions include training and careers advice for claimants.

However, previous research indicates that it is largely the interaction with a personal adviser and ... the quality of that relationship' which determines the degree to which claimants experience the service they receive as personal ( $\mathrm{McNeil}$, 2009: 35). Thus, regardless of the policies in place, some claimants may feel that advisers do little more than 'process benefits' (Bachelor, 2009: 2). Participants in McNeil's (2009: 38) focus groups, for example, complained specifically of 'the lack of a personal approach from advisers'.

In addressing the matter of personalisation in practice, then, it is crucial to consider not only what advisers talk about during work-focused interviews (the substance of the interview), but how they do it (the process of the interview). An advantage of the study reported here is that the recordings allowed us to do both. Using the methodology of Conversation Analysis (CA), we show that personalisation, as it was realised in our dataset, reflects these two key dimensions: the substantive and the procedural. In the main body of this paper, we first illustrate these dimensions in practice, showing how each represents a continuum. We then propose a typology of personalisation in practice, reflecting how the two dimensions interact. We conclude with some thoughts on how our findings might have relevance for advisory practice in the future under the Coalition government's new Work Programme.

\section{Methods}

We made 243 recordings between July 2007 and June 2008, in eight Jobcentre Plus offices and two private sector Employment Zones across four regions of England 
(the latter are not the focus of this paper). Forty-seven advisers took part. It was not possible to calculate a participation rate for advisers, but it was high for claimants: almost 80 per cent of those approached agreed to be recorded. The sample included work-focused interviews (WFIs) with:

- lone parents claiming Income Support;

- people claiming an incapacity benefit due to ill health or disability; and

- people claiming Jobseeker's Allowance while unemployed.

Commissioned by the Department for Work and Pensions (DWP) to use Conversation Analysis (CA) to identify 'effective practice' in WFIs, our remit was the adviser-claimant interactions alone. This reflects the recognition by DWP policymakers that CA redresses a key limitation of more common research methods, i.e. that interviews, focus groups and questionnaires rely on respondents' recall of past events. We know that such recollections can be incomplete, inaccurate or subject to 'reframing' over time (see Waitzkin, 1985). Moreover, a respondent cannot be assumed to remember the exact words used in a prior interaction. Yet we know that small changes in wording can have a significant impact on those interactions (Heritage et al., 2007).

Likewise, quantitative outcome measures (e.g. job entry figures) allow only an indirect inference about the role of the WFI among multiple other factors; they cannot illuminate specifically what was effective about the adviser-claimant interaction. The question of 'what works' during WFIs can only be comprehensively answered through an examination of the specificities of what gets said. Yet little is known about this. It is this gap that the present study was commissioned to address.

In accordance with the methodology of CA (see Drew and Heritage, 1992; Heritage and Clayman, 2010), we worked inductively and on the understanding that talk is a means to perform some action/activity, such as making a Jobseeker's Agreement. Since the same action may be accomplished in different ways, the key question is not whether something occurred, but how it was accomplished. Analysis thus begins with transcribing recordings in detail to show how turns at talk were produced, using symbols to represent features of the timing and manner of speech (see Appendix Table A1 for a key). Next, collections are made of all instances of phenomena of analytic interest, e.g. advisers asking claimants for job goals or providing information about available support. The aim is to identify the range of ways in which the same activity was performed and the consequences - within the interaction - of these differences.

Markers of effectiveness, then, are internal to the interview, e.g. claimant responses which indicate greater understanding or engagement with the activities being undertaken, a commitment to carry out an agreed step towards work or a visible 'turn around' in the claimant's stance towards such a step (Drew et al., 2010). This analytic approach is crucial for identifying effective practices that 
are under the direct control of the adviser, providing an evidence base regarding what works to mobilise claimants, there and then, during the WFI.

We are aware that the presence of recording equipment might have influenced the interactions in our sample. Hence, we made particular efforts to minimise our impact: the camera was discrete and no researcher was present during the WFIs. We were reassured by participants often commenting, unprompted, that they quickly forgot they were being recorded, a finding consistent with studies that have shown 'that the effect of video becomes negligible in most situations after a certain phase of habituation' (Knoblauch et al., 2006).

\section{Dimensions of personalisation in practice: 'substantive' and 'procedural'}

There is clear evidence in our dataset of two dimensions to personalisation in advisers' practice. We call these substantive and procedural personalisation. In this section, we describe each, showing how it operates in Jobcentre Plus interviews. In subsequent sections, we show how each represents a continuum and how these may intersect to produce varying degrees of personalisation.

Substantive personalisation refers to the adviser's capacity to provide services that are tailored to claimants' needs and circumstances. It refers to the substance of the support on offer, the 'what' of service provision. Procedural personalisation refers to the 'how' of service provision, to the ways in which the adviser approaches the interaction with the claimant. It refers to the process undertaken by advisers when delivering their part of the service.

The following extract illustrates both dimensions. The claimant - a lone parent receiving Income Support - is attending a mandatory annual WFI. At the time, she was not required to seek work due to her child's age. However, through her adviser, she could access support to prepare for future work. This extract is long, but well illustrates how the adviser elicits the claimant's needs as a basis for providing tailored advice.

\section{Extract $1\left[003,{ }^{1}\right.$ Lone Parent WFI]}

Some details have been omitted due to space constraints (indicated by “...”); boldface indicates sections of key relevance to the analysis.

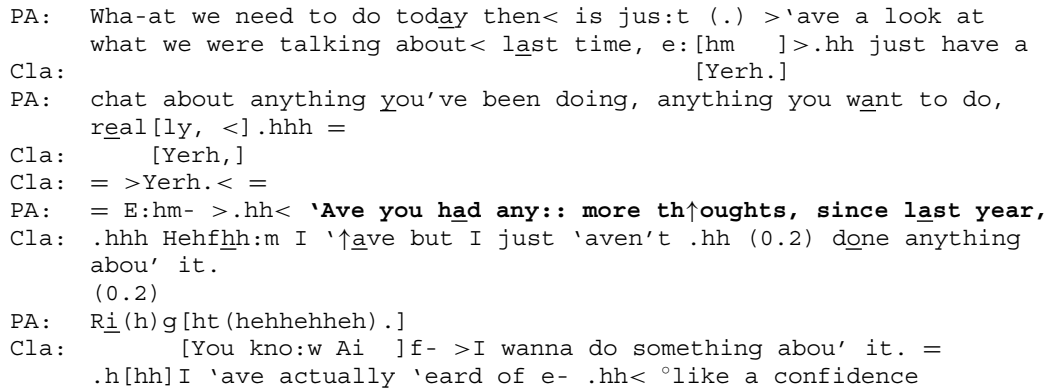


$\mathrm{PA}: \quad[\mathrm{Mm}$.

Cla: class,

$\mathrm{PA}: \quad \mathrm{Mm}[\mathrm{hm}$,

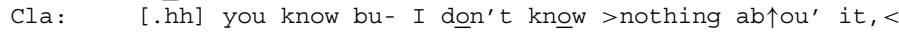

PA: When- when you say >confidence I mean ther- (0.2) might sound a bit silly but people mean different< things by: confidence, .hhh $(0.2)$

Cla: Think 'f g[etting bac]k into the work, ${ }^{\circ}$ (perhaps) ${ }^{\circ}$ Getting (.) PA: $\quad[>$ Is $i t-<]$

Cla: back into it,

PA: If I was to say to you (0.7) what would it take to- actually get you into work, $(0.3)$ what d'you think would be $(0.3)$ your first or your main $(0.6)$ issue,

$(0.3)$

PA: ( ${ }^{\circ}$ if you like, $\left.{ }^{\circ}\right)$

Cla: E:hmf: (0.3) finding a job,

PA: We were just take a step back a little bit. e:hm .fhhh (1.1) Do you have: : (0.6) ideas of the kind of work you want to do. first of all.

Cla: .hhh E:hmfhh >.hh< I was thinking abou' the social work,

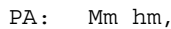

Cla: But then I've actually been thinking abou' teaching assistant?

PA: We talked last time about a few places that might be able to help you... there's a voluntary agency in ((place name))... I think what you need to do though (.) is: first of all try and pinpoint which are[a you're] most likely to move towards: .

Cla: [Yeah. ]

$\mathrm{PA}: \quad>\cdot \mathrm{h}[\mathrm{h}<\mathrm{an}] \mathrm{d}$ then if you want to use some voluntary work as $\mathrm{Cla}: \quad$ [Yeah.]

$\mathrm{PA}$ : work ex[perie]nce $>. \mathrm{hh}<$ they can find you something a bit more Cla: [Yeah.]

PA: specific. $(0.3)$ to fit. $(0.4)$ with what you want to do... then we can start looking at all the different options, = $\mathrm{Cla}:=\overline{\mathrm{Y}}[\mathrm{eah}$.

$\mathrm{PA}: \quad[>. h \mathrm{~h}<]$ At what sort of work experience what sort of qualifications you might ne $[\bar{e} \bar{d}$, .hhhh-

[Yeah. = >I think $<$ ] the main one is

$\mathrm{Cla}$ : >really then gonna be $<$ like the secretary work, =

$\mathrm{PA}: \quad=$ Right. $=$

Cla: [.hh I think I]'d rather (0.1) just go straight into ${ }^{\circ}$.hh (0.1) PA: [Yeah. .hhh ]

Cla: cler $\left[\right.$ ical. ${ }^{\circ}=>$ But then I s]till< need to train fe-cuz I need

PA: $\quad[$ Yeah. $=>$ Well I me-<]

Cla: (0.1) compu'er (0.3) >quali[fications< and thi]ngs

$\mathrm{PA}$ :

Cla: like th [at.]

PA: $\quad[Y e] a h . . . I t ' s-(0.4)$ 'aving the information so that yeyou can make $(0.1)$ the choice yourself.

PA: E:hm: : hh Now, there's a couple of things I could suggest to you, if you $>$.hh $<$ you want some help right from the start... Surestart run something called skills coaching...> Lot of $<$ people (.) <will do that through Learn Direct:>.(0.2) because of the flexibility of doing it, ... The other place that we often: $(0.2)$ eh refer people to is $(($ centre $\mathbf{x}))$ ):, ... what they've got on here is actually (0.1) eight modules. that you could take part in. .hh The only one you $\downarrow$ have to do is an induction... the $\uparrow$ others $(0.1)$ you can choose $(0.1)$ as few or as many, (0.1) as you want to do... Related to this they have all sorts of >other projects $<$ at the $(($ centre $\mathrm{x}))$, .hh So- If there was something else between you; you identified (0.1) that you needed to do .h[hh] 


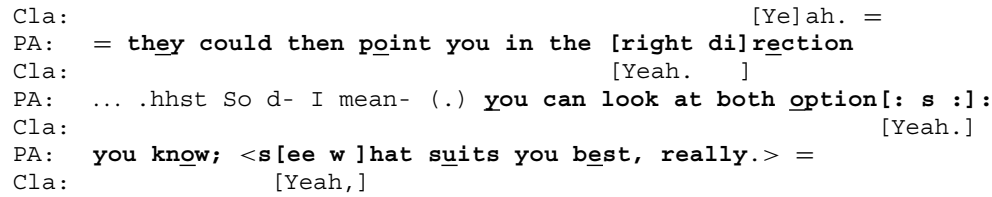

In this extract the claimant is clear that she wants to work but feels illequipped to do so. Across the interview, she raises the possibility of a confidence class (lines 14-16), her interest in a job as a social worker or teaching assistant (lines 34-37), her enjoyment of administrative work (data not shown) and her need for training in computer and other clerical skills (lines 52-61). In response, the adviser describes several options, including voluntary work (lines 39-47), skills coaching (lines 64-74), plus the possibility of courses through Learn Direct (lines 66-68).

Substantive personalisation is evident, then, in two ways:

- The adviser is able to offer the claimant a variety of support services/training courses from which she may choose.

- The programmes themselves are flexible (e.g. at centre $\mathrm{x}$, she will be able to choose from eight modules and will be given advice about other support she might receive, lines 68-77).

Thus the substance of the support on offer can be (somewhat) tailored to the individual, and that individual has a say in what kinds of support she receives.

In addition, this tailoring is facilitated by the approach the adviser takes to the interaction. Procedural personalisation is also evident, then, in several ways, including:

- The series of open questions used by the adviser to elicit the claimant's thoughts about work (line 8), her support/training needs (lines 19-20), her perceived barriers to work (lines 25-27) and her job goals (lines 31-33). These create 'slots' in the interaction for the claimant to describe her circumstances in her own terms.

- The claimant's responses to these questions are used by the adviser as a basis for selecting options to consider with the claimant. This is particularly evident in her exploration of what the claimant means by 'confidence' (lines 19-20) in order to establish what kind of course might suit her, and her insistence that the claimant start by deciding what kind of work she wants, so that the training will 'fit' (lines 40-51) her goals. In this way, the adviser demonstrates that any advice she offers will be rooted in the claimant's circumstances;

- She also explicitly hands the decision over to the claimant (lines 62-63, 79-81).

Extract 1 shows that advisers were, in our recordings, offering claimants some choice. Equipped with knowledge about the available options and supported by 


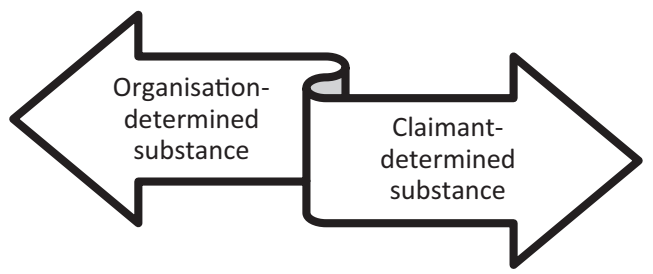

Figure 1. Substantive personalisation as a continuum

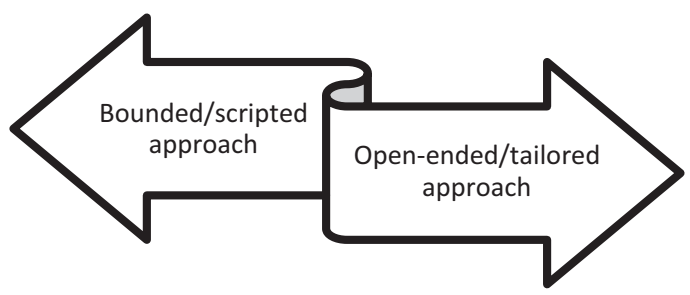

Figure 2. Procedural personalisation as a continuum

the state to make these options available, advisers were empowered to offer a (somewhat) flexible service. This extract also demonstrates a more subtle sense in which the personalisation agenda can be evident in practice - in the detail of the adviser's communication with claimants. This dimension is less dependent on what advisers do and more on how they do it. Procedural personalisation is, therefore, less directly influenced by policy since advisers can accomplish the same task with or without addressing the claimants' specific needs, as we will show.

\section{The dimensions as continua}

Each of these dimensions reflects a continuum, rather than a set of binary alternatives (i.e. personalised or not). With respect to the substance of the interview, this continuum ranges from more organisation-determined to more claimant-determined, as depicted in Figure 1. To illustrate, imagine a service that is entirely organisation-determined: whatever the claimants' experience and goals, they might all be required to attend the same training programme. At the other extreme, an entirely claimant-determined service would provide whatever the claimant needed to get the job they wanted.

For the procedural aspects of the interview, the continuum ranges from an advisory approach that is strictly 'bounded', to one that is more open-ended, as depicted in Figure 2. Again, if we consider the extremes, an adviser might ask the claimant a list of questions - like in a structured survey - with pre-determined alternatives from which to choose. When delivering information, they might follow a script, providing the same information to every claimant. At the other 
extreme, they might take an entirely open approach - like in person-centred counselling - asking broad, open questions and providing information tailored to the claimants' expressed needs.

None of the interviews in our dataset fully embodied such extremes. However, there was substantial variability - along the continua between these extremes - in how advisers addressed the interview tasks. Extracts 2 and 3 offer a striking contrast with respect to both dimensions of personalisation (for a related analysis of Extract 2, see Toerien et al., 2011). The facts of the two cases are closely matched. The claimants, both under twenty-five, have recently completed degrees in graphic design and/or photography. Neither has much work experience but both want to work in their field. Both are claiming, for the first time, Jobseeker's Allowance, the main state unemployment benefit at the time of recording. They are required to complete a Jobseeker's Agreement, which includes a statement of their job goals. Both advisers record the claimants' specialisms. Both also note that there are few suitable vacancies available in the local area (each in different parts of the UK). In Extract 2, however, the adviser insists on an additional 'back up' (line 7) goal that is more 'realistic' (lines 13-15), while in Extract 3, the adviser grants the claimant a 'permitted period' (lines 36-41).

The consequences are significant: the claimant in Extract 2 is required to start looking for jobs in retail immediately or risk losing benefits; the claimant in Extract 3 has thirteen weeks, on benefits, in which to seek work in his field. Moreover, the claimant in Extract 3 receives some information about support to become self-employed (see lines 18-35), an option that could allow him to pursue his goal despite the limited vacancies. By contrast, in Extract 2, the adviser introduces the (generic) possibility of training only to dismiss its relevance for this claimant without exploring the options (see lines 33-42); self-employment is not discussed. In a substantive sense, then, these cases represent opposing points on the continuum in Figure 1. The support offered in Extract 3 is fitted to the claimant's primary job goals; in Extract 2, it is not.

\section{Extract 2 [067; New Jobseeker WFI]}

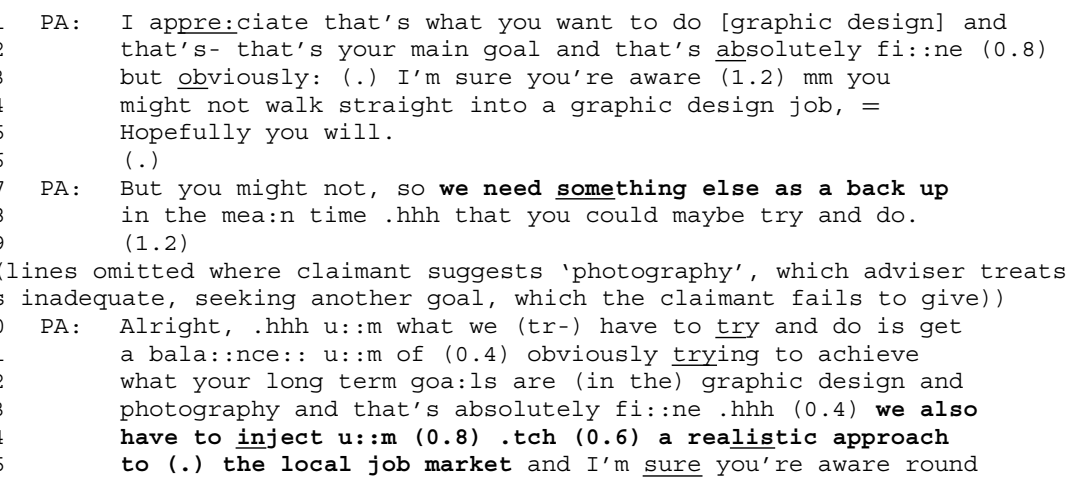




\section{Extract 3 [102; New Jobseeker WFI]} Cla: $\quad[\mathrm{Mhm}$ that job. Cla: Sure yea[h could- we could look into it.

PA :

PA: [Yeah PA: $\quad[($ ) Cla: [Yea : : h thing. (3.2) ((typing)) self-employed $=0: r(0.2)$ [um, to get an actual job.

PA: Yea [h. Oh yeah yeah.] b [e self-employed >anyway $<$.

PA: Because there's uh: =

Cla: = Yeah

he:re there's not a great deal in the way of graphic design

PA: .hh What I'm saying is (0.4) w- i-s-for example say it took six months $(0.2)$ to get a job as a graphic designer

(.) that's not- unrealistic that could well be the ca: se: (.) and then you might end up with a great job and a great future. hh but in the mea: : ti:me (1.0) the governme [nt would rather you were working s:omewhere e:lse

PA: than claiming benefit for six months while you looked for

PA: in the mean time (.) we have to think of something (.) \#uh\#

PA: [along a different line [yeah?
Cla: [But-am I u: :m (1.8) .tch

yeah just- (0.2) p- I would just go: for retail then?

PA: O: :kay .hhhhh (0.4) W: hat I will s: : tell you at this stage is nothing here is set in sto: ne..

PA: S: : : ometimes at this point with- (0.4) people we- we-talk about trai: : ning... in your ca: se (.) (b-) you- you may agree with me .hh there's not really any point in that you've just spent years training to get where you a: :re (.) u:m and the sortof training we: have would be (.) a little below the level of what you've done. .hh but if in the future you ever have a change of direction $0:$ : r (0.4) you feel there's something extra you want .hhh just so: (as) long as you're aware we do have: that sort of facility $(0.6)$ um: : can't guarantee anything but you know we

PA: So d'you do sort of- (0.2) during construction and things like that (one of:) sort of (.) photographs as it goes along.

Cla: U: :m not re:ally I suppose er-because: : um (1.2) I('ve) mainly trained in um: (.) advertising, so: [: commercial stuff $=\overline{\text { so }}$ $[\mathrm{Mm}$ :

Cla: portrai:ts and: that [kind of thing. = But I'd like to

Cla: incorporate that in: [as well as the architectural stuff 'cos

Cla: I've always (.) .hhhh sort of been interested [(in it) really,

$\begin{array}{ll}\mathrm{PA}: & \text { [Is there not a }\end{array}$ big sort of um: (1.0) e::r (.) gap now in the market with er $(0.2)$ cos ((company name)) have closed down in the las:t (0.4) >couple of week [s< haven't they so: [have you thought that's: [Yeah there's-

PA: that'd be quite a big player out of ((name of town)) sort of

PA: Um: (0.2) Okay. .hh so: we'll put photographer.

PA: So have you got, $-($.$) looked into (0.6)$ the: $(0.4)$ side of being

Cla: [.HHHH Yea: :h well: (.) the thing about (.) photography is the fac- that (0.2) you're very hard pressed

Cla: [in photography, ] so I mean mo:st of it you have to

PA: [Yeah (but) I mean have you: studied] the business side of it, of um: : tax and all that sort of stuff [:.

Cla:
$[\mathrm{Mm}$ :

PA: Business Link can help you with setting up a business sort of 


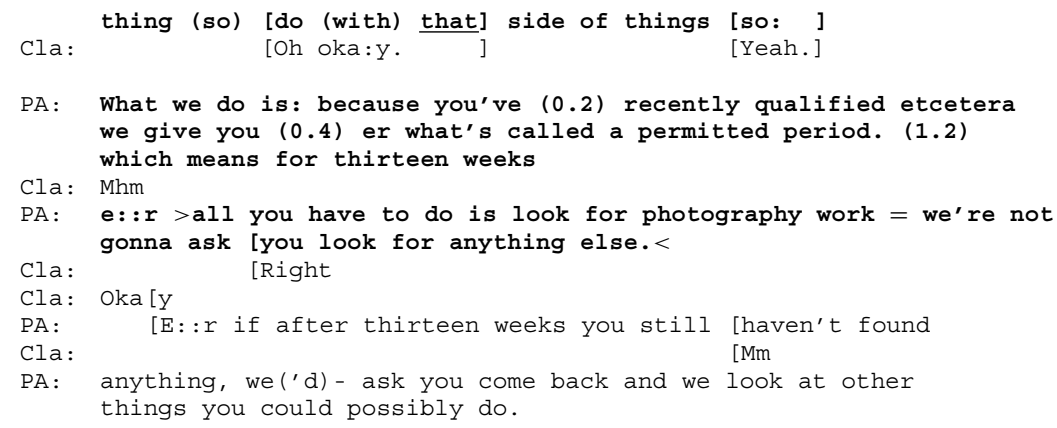

These two advisers also take very different approaches to managing the interaction with the claimant. In Extract 2, the adviser moves quickly from recording the claimant's primary job goals to insisting on a more 'realistic' backup (see line 14). He assumes, then, that the primary goals are unrealistic and closes down discussion thereof. In Extract 3, by contrast, the adviser spends time questioning the claimant about his primary goal (only some of these questions are shown above due to space constraints; e.g. lines 1-2, 11-17, 20-21, 28-29), thereby opening up the discussion. The consequences are, again, significant. In Extract 3, the claimant is encouraged to consider ways in which he might make his goal a reality. In Extract 2, the adviser and claimant are at odds, with the claimant insisting on job goals in line with his qualifications and the adviser insisting on something more generally available. The claimant subsequently volunteers two pertinent facts: that he has a job interview lined up and is prepared to relocate. Both suggest that his goals might be more realistic than the adviser - having failed to elicit this information through the kind of questioning evident in 3 assumed. Rather than taking the claimant's circumstances as his starting point, he opts to foreground his organisational mandate to 'inject a realistic approach to the local job market' (lines 13-15), and government policy on unemployment (lines 21-25). The result is a reluctant agreement by the claimant to record 'retail' as a 'back up' (lines 29-30) - a goal reflecting neither his training nor aspirations.

Both advisers are operating within the same, potentially conflicting, policy constraints: they can offer appropriately qualified claimants a 'permitted period' and should ensure that claimants have 'realistic' job goals. In these extracts, they each take an alternative route, providing substantively different kinds of support. In addition, our analysis shows that advisers have to navigate another choice not just whether to offer a permitted period, but how to manage the talk about job goals. In the cases above, one adviser foregrounds his organisational mandate (to record a 'realistic' goal), whilst the other focuses on exploring the claimant's goals/circumstances; one provides generic information (about training), whilst the other tailors his advice to what the claimant has revealed about his needs; one considers only standard approaches to the labour market, whilst the other 
TABLE 1. The intersection between substantive and procedural personalisation

\begin{tabular}{lll}
\hline & $\begin{array}{l}\text { Bounded/scripted } \\
\text { approach }\end{array}$ & $\begin{array}{l}\text { Open-ended/tailored } \\
\text { approach }\end{array}$ \\
\hline $\begin{array}{l}\text { Organisation-determined substance } \\
\text { Claimant-determined substance }\end{array}$ & $\begin{array}{l}\text { 1. Non-personalisation } \\
\text { 3. Partial personalisation }\end{array}$ & $\begin{array}{l}\text { 2. Partial personalisation } \\
\text { 4. Strong personalisation }\end{array}$ \\
\hline
\end{tabular}

explores strategies for creating suitable employment. In a procedural sense, then, these cases represent opposing points on the continuum in Figure 2. The adviser in Extract 2 takes a more bounded or scripted approach - one that is primarily led by the organisation's requirements; the adviser in Extract 3 takes a more open-ended approach - one that is more tailored to what he knows about the claimant.

\section{Connecting the substantive and procedural: a typology of personalisation in practice}

If we think of substantive and procedural personalisation as two dimensions of personalisation in practice, we can construct a typology representing how they interact. This is illustrated in Table 1 above. The rows represent the extreme ends of the substantive continuum (Figure 1). The columns do the same for the procedural continuum (Figure 2). In Quadrants 1 and 4, the substance and procedure are in accord: in 1, the substance is pre-determined by the organisation (i.e. non-personalised), and advisers take a bounded and scripted approach to the procedure (i.e. non-personalised); in 4, the substance is determined by the claimant's needs/circumstances (i.e. personalised), and advisers take an open and tailored approach to the procedure (i.e. personalised). Thus, we see how the intersection between the continua can give rise both to non-personalised (Quadrant 1) and strongly personalised (Quadrant 4) welfare-to-work service provision.

The intersection also means that partial forms of personalisation - lying anywhere along the two continua - are possible. This can, as Quadrants 2 and 3 illustrate, give rise to tensions between the modes, where the adviser may take an open-ended approach, yet have little to offer that would fit the claimant's needs (Quadrant 2), or, alternatively, the services on offer may be flexible, but the adviser's approach may be largely scripted (Quadrant 3). In our dataset, for example, some advisers took care to elicit claimants' goals/needs and to provide appropriate tailored advice. Substantively, however, they were not in a position to provide the additional training needed. Likewise, when talking with claimants about how they might find work, some advisers explored what claimants were already doing by asking open questions. The advisers taking this (more personalised) approach, however, had no means of providing more personalised substantive support than those who took a more scripted approach. 
At best, the personalised approach helped claimants to think through their options more carefully; at worst, it was a form of 'whitewash', concealing the fact that - regardless of how they answered the adviser's questions - the same basic weekly 'steps towards work' would be recorded on the Jobseeker's Agreement.

Conversely, although many claimants had the right to choose from a range of support programmes (i.e. some degree of substantive personalisation was operating), these were often presented in a scripted fashion, e.g. advisers read from standard information sheets, providing no indication of the relevance to the individual's circumstances and leaving it to the claimant to decide later which programme (if any) to attend. Because this approach relies on the claimant both recognising how a programme might be of use and taking the initiative to contact the adviser for a referral, it risks working against claimants realising their right to choose. For a range of reasons claimants might never take up the support on offer. There is some evidence in our dataset that such difficulties could be overcome if advisers took a more personalised approach to talking about the available programmes. Although we do not have sufficient data to draw statistically significant conclusions, we found that lone parents only ever signed up - during the interview - to further support through the New Deal for Lone Parents if advisers issued an explicit invitation; simply providing generic information about NDLP was never enough (Drew et al., 2010).

\section{Discussion}

Focusing on adviser-claimant interaction in over 200 recordings, this paper has addressed the question of how advisers implement personalisation within workfocused interviews in Jobcentre Plus. In our dataset, substantive personalisation amounts to flexibility in service provision, such that claimants receive services that are (at least to some extent) determined by their needs and circumstances; procedural personalisation involves taking a personal approach to interacting with claimants, such that the WFI is shaped (to some extent) around the claimant's 'story'. To enact personalisation in a strong sense, then, advisers need to have both the resources to provide substantively flexible services and the skills to take a personal approach to the interaction.

The rhetoric of personalisation implies the promise of strong personalisation (i.e. Quadrant 4 in Table 1). From the slogan displayed in Jobcentres at the time of recording - assuring claimants of 'the job you want, the help you need' - to the Coalition government's new Work Programme, which aims explicitly 'to create a system that treats people as individuals and allows providers greater freedom to tailor the right support to the individual needs of each claimant' (Bellis et al., 2011: 17), the message is that substantive and procedural personalisation will be delivered. However, our analysis shows that the two dimensions need not come together in practice, resulting in partial or even non-personalised services. 
In our view, there are at least two institutional barriers that make strong personalisation difficult to implement within Jobcentre Plus. First, for each interview type, there is a set of tasks (sometimes referred to as the 'must do' list) that advisers are expected to complete - either for every interview or in a percentage of cases. Second, advisers' job performance is partially assessed through observation by a manager, using a checklist to record whether or not (rather than how) they perform certain activities. Moreover, most policy initiatives around personalisation have focused on the substantive dimension, leaving largely untouched the question of how to create an environment in which a personal approach to the WFI is enabled. ${ }^{2}$ It is not surprising, then, that cases like those in Extracts 1 and 3 reflect moments of greater personalisation in what were otherwise often highly standardised interviews. ${ }^{3}$ We would argue that they represent efforts by advisers to work around the system as it was organised at the time of recording, i.e. to create space amidst the checklists and form filling to generate something of a more 'personal relationship' with claimants.

The typology presented here offers a way of thinking about the trade-offs that accompany different ways of implementing the personalisation agenda. Each of the partial forms of personalisation carries risks: Quadrant 2 of Table 1 - with its tailored approach to the interview but organisation-determined substance could be interpreted as a form of covert manipulation of the claimant; ${ }^{4}$ Quadrant 3 - with its claimant-determined substance but scripted approach - may well result in missed opportunities to engage claimants in available support. Nonpersonalisation (Quadrant 1) appears to carry the greatest risk of claimant disengagement and dissatisfaction but strong personalisation (Quadrant 4) is risky too as adviser control is diminished. One implication is that, while the personalisation agenda can be seen as consistent with the principles of ' $\mathrm{New}$ Public Management', there are clearly tensions within New Public Management approaches that have yet to be reconciled in the delivery of WFIs in Jobcentre Plus, e.g. some of its methods (such as targets and checklists to improve the 'customer experience') may actually serve to diminish that experience.

If the policy environment in 2012 was the same as when our recordings were made we would be able to offer strong conclusions about how personalisation could be enhanced through adviser training (the study report makes a series of such recommendations - see Drew et al., 2010). However, since the time of recording, UK policy on welfare-to-work has changed radically. Under the Coalition government's Work Programme, services for long-term claimants have been contracted out to organisations in the private and third sectors, who employ their own staff of advisers and practitioners. This does not mean that the need for Jobcentre Plus advisers to offer personalised services is decreasing; claimants will still attend Jobcentres for up to a year before referral to a Work Programme provider. The Department for Work and Pensions therefore still has a role to play in training its staff to offer more personalised services. What the DWP has 
little influence over, however, is how personalisation is enacted on the frontline by Work Programme providers or their sub-contractors.

Work Programme contracts are based on payment by results (more specifically for getting people into sustained employment for six months or more). How contractors get people into work is for them to determine; they have almost complete discretion in how they organise the delivery of their back-towork programmes:

Previous UK welfare-to-work programmes specified in varying levels of detail what interventions providers had to deliver. The Work Programme, in contrast, gives providers far greater flexibility to design programmes that will work ... (The) government is providing freedom for providers to personalise support for the individual in a way that fits the local labour market. This is sometimes referred to as a 'black box' commissioning approach. (DWP, 2011)

Details of the contracts let by DWP are publicly available 5 and show that organisations holding 'prime' contracts have set up networks of sub-contractors to provide specific services (e.g. help with CV writing) or specialist services (e.g. help for people with mental health conditions or drug and alcohol problems). The lists of sub-contractors imply that frontline contact with Work Programme clients will potentially be dispersed among hundreds of organisations. It is unclear, therefore, how the promises of personalisation that appear in policy documents and the announcements of senior politicians and officials (like those cited at the head of this article) can be made good in practice when the 'black box' approach implies that DWP and JCP will have no control over what happens on the frontline. The experiences of Work Programme clients may emerge in future but at the time of writing there is no research to draw on. Evidence from Australia offers a cautionary tale though. Considine et al. (2011: 811) have shown that the privatisation of the Australian employment sector has not achieved 'the enhanced levels of flexibility so often identified as a desirable outcome of reform'. In fact, over the ten years during which full privatisation has been accomplished (1998-2008), there has been 'a marked increase in the level of routinisation and standardisation on the frontline' (ibid.). What will happen in the UK is unclear. However, while personalisation remains a core principle of welfare-towork reform there will be a need for well-grounded evidence about how this principle can be operationalised - whoever is responsible for implementation.

This paper contributes to the debate around what personalisation means. Like previous efforts to 'unpick personalisation' (see Cribb and Owens, 2010), we have shown that the concept is multi-dimensional. Unlike most work in this area (see Borghi and van Berkel, 2007: 421), however, we have focused not on formal policy-making but on the ways in which policy may be enacted on the frontline. This is crucial because, as Yeatman (2009: 233, emphasis in original) argues, 'the point of service delivery is the critical level at which the democratisation and individualisation of service delivery can occur'. To study 
this 'critical level' directly, we have used Conversation Analysis to examine the detail of recorded WFIs. Like any approach, this has its limitations. Our study was not designed, for instance, to identify the possible factors underlying the different practices we observed. Further research might explore whether factors like adviser training, years of experience, financial incentives to get people into work and other policy changes might offer partial explanations. These are important empirical questions. However, they should not supplant a focus on the interactions themselves. An evidence-based understanding of how personalisation policies are enacted is necessary both for assessing whether policies are translating into the intended practice, and also for taking seriously the direct impact of policy on service users. Failure to add this interactionbased perspective to policy debates risks producing unintended consequences (cf. Antaki et al., 2009), generated out of the inevitable gap between rhetoric and everyday practice.

\section{Acknowledgements}

The study was funded by the UK's Department for Work and Pensions. The authors would like to thank the advisers and claimants who made the study possible, and the DWP and JCP managers, policymakers and researchers who supported this new approach to exploring the advisory role. The authors are also very grateful to the editors and two anonymous referees for their insightful comments on an earlier draft of this paper. Please note that the views expressed in this report are not necessarily those of the Department for Work and Pensions or any other UK Government Department.

\section{Notes}

1 Numbers in the extract headings indicate unique identification codes for the recordings.

2 Analysis of the extent to which policy initiatives have translated into substantive personalisation in practice is beyond the scope of this paper. However, based on our observations of WFIs, it seems likely - as one anonymous referee suggested - that even on the substantive dimension, welfare to work projects have left relatively little scope for advisers to offer tailored services.

3 It would be misleading to categorise advisers or interviews according to the typology depicted in Table 1 because advisers usually took different approaches to different tasks even within a single interview. However, there was little evidence of strong personalisation in our dataset, and, overall, the balance was in favour of more scripted approaches and more organisationdetermined substance. This was particularly the case in interviews with claimants who were required to be looking for work. Somewhat more flexibility was evident in cases where claimants could defer looking for work due to incapacity or childcare commitments.

4 We are grateful to the editors for drawing our attention to this implication of our analysis.

5 See http://www.dwp.gov.uk/policy/welfare-reform/the-work-programme/.

\section{References}

Antaki, C., Finlay, W. M. L. and Walton, C. (2009), 'Choices for people with intellectual disabilities: official discourse and everyday practice', Journal of Policy and Practice in Intellectual Disabilities, 6: 260-6. 
Bachelor, L. (2009), 'Jobcentres are just there to process benefits', Guardian (Work), 5 September, p. 2, available at http://www.guardian.co.uk/money/2009/sep/o5/jobcentres-benefits (last accessed 25/1/2012).

Bellis, A., Oakley, J., Sigala, M. and Dewson, S. (2011), Identifying Claimants' Needs: Research into the Capability of Jobcentre Plus Advisors, BIS research paper number 43, available at http://www.bis.gov.uk/assets/biscore/higher-education/docs/i/11-935-identifyingclaimants-needs-research-jobcentre-plus-advisors (last accessed 25/1/2012).

Borghi, V. and van Berkel, R. (2007), 'Individualised service provision in an era of activation and new governance', International Journal of Sociology and Social Policy, 27: 413-24.

Carr, S. (2008), Personalisation: A Rough Guide, London: Social Care Institute for Excellence.

Christensen, T. and Laegreid, P. (2011), The Ashgate Research Companion to New Public Management, Farnham: Ashgate.

Considine, M., Lewis, J. M. and O'Sullivan, S. (2011), 'Quasi-markets and service delivery flexibility following a decade of employment assistance reform in Australia', Journal of Social Policy, 40: 811-33.

Cribb, A. and Owens, J. (2010), 'Whatever suits you: unpicking personalization for the NHS', Journal of Evaluation in Clinical Practice, 16: 310-14.

Cutler, T., Waine, B. and Brehony, K. (2007), 'A new epoch of individualization? Problems with the "personalization" of public sector services', Public Administration, 85: 847-55.

Department of Social Security (1998), New Ambitions for Our Country: New Contract for Welfare, UK Government Green Paper, London: The Stationery Office.

Department for Work and Pensions (2008a), No One Written Off: Reforming Welfare to Reward Responsibility, UK Government Green Paper, London: The Stationery Office, available at http://www.dwp.gov.uk/policy/welfare-reform/legislation-and-keydocuments/no-one-written-off/ (last accessed 25/1/2012).

Department for Work and Pensions (2008b), Raising Expectations and Increasing Support: Reforming Welfare for the Future, UK Government White Paper, London: The Stationery Office, available at http://www.dwp.gov.uk/policy/welfare-reform/legislation-and-keydocuments/raising-expectations/ (last accessed 25/1/2012).

Department for Work and Pensions (2011), The Work Programme, London: Department for Work and Pensions.

Drew, P. and Heritage, P. (1992), Talk at Work: Interaction in Institutional Settings, Cambridge: Cambridge University Press.

Drew, P., Toerien, M., Irvine, A. and Sainsbury, R. (2010), 'A study of language and communication between advisers and claimants in work focused interviews', Department for Work and Pensions, Research Report 633, available at http://php.york.ac.uk/inst/ spru/pubs/1742/ (last accessed 29/10/2012).

Duncan Smith, I. (2010), Speech: 'Welfare for the 21st century', 27 May, available at http://www.dwp.gov.uk/newsroom/ministers-speeches/2010/27-05-10.shtml (last accessed 24/2/2012).

Ferguson, I. (2007), 'Increasing user choice or privatizing risk? The antinomies of personalization', British Journal of Social Work, 37: 387-403.

Freud, D. (2007), Reducing Dependency, Increasing Opportunity: Options for the Future of Welfare to Work, an independent report to the Department for Work and Pensions, available at http://www.dwp.gov.uk/policy/welfare-reform/legislation-and-key-documents/freudreport/ (last accessed 25/1/2012).

Gregg, P. (2008), Realising Potential: A Vision for Personalised Conditionality and Support, an independent report to the Department for Work and Pensions, available at http://www. dwp.gov.uk/policy/welfare-reform/legislation-and-key-documents/realising-potential/ (last accessed 25/1/2012).

Greener, I. and Powell, M. (2008), 'The evolution of choice policies in UK housing, education and health policy', Journal of Social Policy, 38: 63-81.

Heritage, J. and Clayman, S. (2010), Talk in Action: Interactions, Identities and Institutions, Chichester: Wiley-Blackwell. 
Heritage, J., Robinson, J., Elliott, M., Beckett, M. and Wilkes, M. (2007), 'Reducing patients' unmet concerns in primary care: the difference one word can make', Journal of General Internal Medicine, 22: 1429-33.

Jefferson, G. (2004), 'Glossary of transcript symbols with an introduction', in G. H. Lerner (ed.), Conversation Analysis: Studies from the first generation, Philadelphia: John Benjamins, pp. 13-23.

Karagiannaki, E. (2007), 'Exploring the effects of integrated benefit systems and active labour market policies: evidence from Jobcentre Plus in the UK', Journal of Social Policy, 36: 177-195.

Knoblauch, H., Schnettler, B., Raab, J. and Soeffner, H.-G. (eds.) (2006), Video Analysis Methodology and Methods, Frankfurt: Peter Lang.

Leadbeater, C. (2004), Personalisation Through Participation: A New Script for Public Services, London: Demos, available at http://www.demos.co.uk/publications/personalisation (last accessed 25/1/2012).

Lipsky, M. (2010), Street-Level Bureaucracy: Dilemmas of the Individual in Public Services (updated edition), New York: Russell Sage Foundation.

Mansell, J. and Beadle-Brown, J. (2005), 'Person centred planning and person-centred action: a critical perspective', in P. Cambridge and S. Carnaby (eds.), Person Centred Planning and Care Management with People with Learning Disabilities, London: Jessica Kingsley Publishers, pp. 19-33.

McNeil, C. (2009), Now It's Personal: Personal Advisers and the New Public Service Workforce, a report by the Institute for Public Policy Research, available at http://www. ippr.org/publications/55/170o/now-its-personal-personal-advisers-and-the-new-publicservice-workforce (last accessed 25/1/2012).

Needham, C. (2011), 'Personalization: from story-line to practice', Social Policy and Administration, 45: 54-68.

Pykett, J. (2009), 'Personalization and de-schooling: uncommon trajectories in contemporary education policy', Critical Social Policy, 29: 374-397.

Stafford, B. and Kellard, K. (2007), 'Reforming the public sector: personalised activation services in the UK', in R. Van Berkel and B. Valkenburg (eds.), Making it Personal: Individualising Activation Services in the EU, Bristol: Policy Press, pp. 12747.

Toerien, M., Irvine, A., Drew, P. and Sainsbury, R. (2011), 'Should mandatory Jobseeker interviews be personalised? The politics of using conversation analysis to make effective practice recommendations', in C. Antaki (ed.), Applied Conversation Analysis: Intervention and Change in Institutional Talk, Basingstoke: Palgrave Macmillan, pp. 14060 .

Valkenburg, B. (2007), 'Individualising activation services: thrashing out an ambiguous concept', in R. Van Berkel and B. Valkenburg (eds.), Making it Personal: Individualising Activation Services in the EU, Bristol: Policy Press, pp. 25-44.

Waite, J. (2009), 'Jobcentre Plus - not working', Face the Facts, Radio 4 documentary, 16 August, available at http://www.bbc.co.uk/programmes/boomok5f (last accessed 25/1/2012).

Waitzkin, H. (1985), 'Information giving in medical care', Journal of Health and Social Behavior, 26: 81-101.

Yeatman, A. (2009), 'Facilitating independence and self-determination: the case of a disability employment service', in A. Yeatman, G. W. Dowsett, M. Fine and D. Gursansky (eds.), Individualization and the Delivery of Welfare Services: Contestation and Complexity, Basingstoke: Palgrave Macmillan, pp. 210-43. 


\section{Appendix}

\section{TABLE A1. Transcription Key (see Jefferson, 2004)}

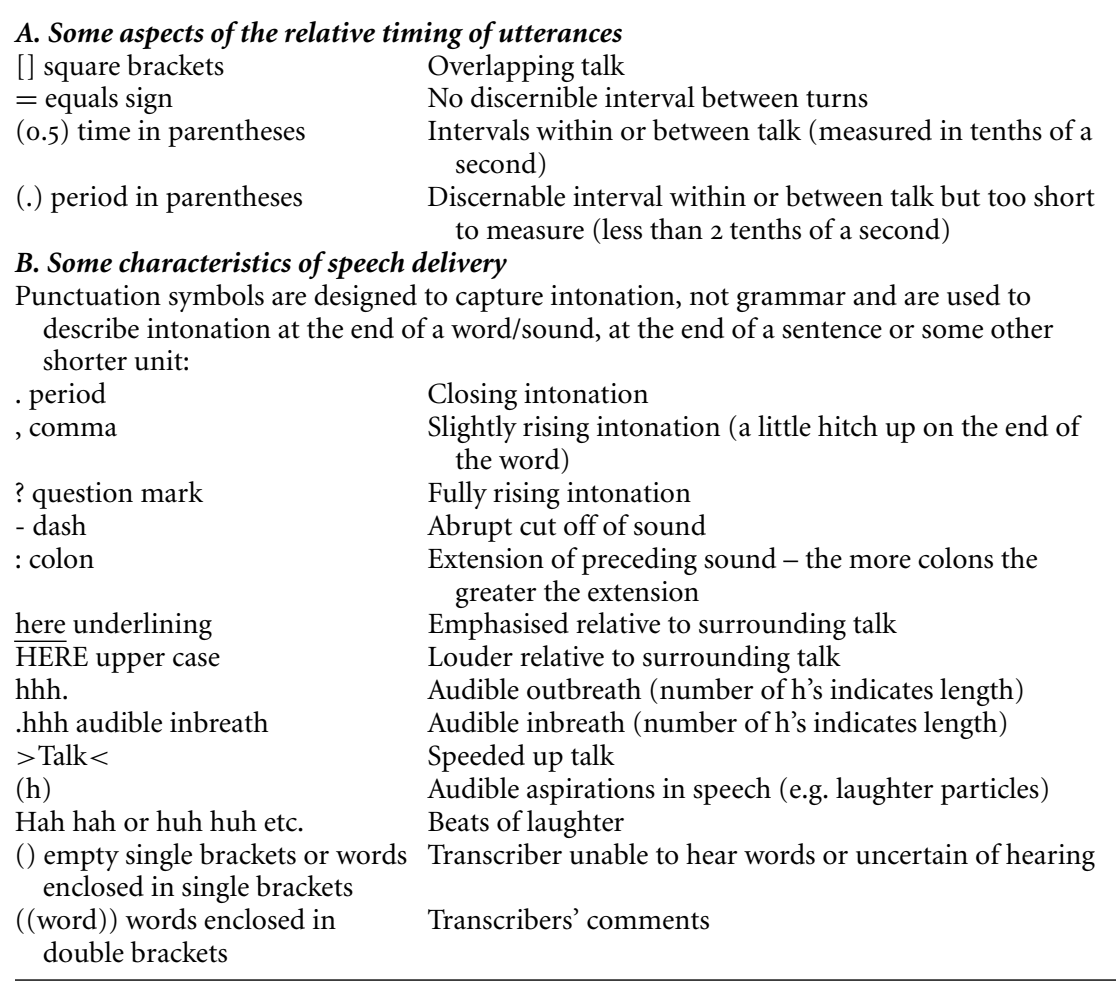

